Jurnal Geocelebes Vol. 1 No. 2, Oktober 2017, 72 - 81

\title{
IDENTIFIKASI BIJIH BESI (Fe) MENGGUNAKAN METODA GEOLISTRIK RESISTIVITAS KONFIGURASI WENNER- SCHLUMBERGER DI KABUPATEN LUWU
}

\author{
Wira Sunarya ${ }^{1}$, Hasanuddin $^{1}$, Syamsuddin $^{1}$, Maria $^{1}, \operatorname{Erfan}^{1}$ \\ ${ }^{1}$ Program Studi Geofisika, Fakultas Matematika dan Ilmu Pengetahuan Alam \\ Universitas Hasanuddin Makassar
}

Penulis koresponden. Alamat email: sunarya_wira@yahoo.com

\begin{abstract}
Abstrak
Telah dilakukan penelitian untuk mengidentifikasi sebaran bijih besi di Kecamatan Walenrang, Kabupaten Luwu, Sulawesi Selatan dengan menggunakan metoda geolistrik tahanan jenis konfigurasi Wenner-Schlumberger. Hasil survey resistivity berupa penampang 2-D dan blok model 3-D yang memberikan informasi mengenai sebaran bijih besi, dimana penyebaran terbesar berada di sebelah barat daerah penelitian dengan arah timur laut - barat daya. Data resistivitas dari penampang resistivitas 2-D yang diperoleh dari pengukuran lintasan 1 sampai dengan pengukuran lintasan 4 di lapangan yaitu zona lapisan bijih besi magnetite berada pada resistivitas $\rho<40 \Omega \mathrm{m}$, zona pelapukan batuan andesit dengan resistivitas $40 \Omega \mathrm{m}<\rho<250 \Omega \mathrm{m}$ dan zona batuan basalt dengan resistivitas tinggi $\rho>250 \Omega m$ yang sesuai dengan yang ditemukan bagian barat daerah penelitian yaitu di lembah buntu Mario dan buntu Sikuku hingga ke buntu Andulan bagian utara ada boulder magnetis yang tersebar di aliran sungai lamasi diperkirakan berasal dari zona potasik.
\end{abstract}

Kata kunci: Bijih besi magnetite, Geolistrik, Resistivitas, Wenner-Schlumberger, Boulder magnetis

\begin{abstract}
This research is conducted in Subdistrict of Walenreng, Luwu Regency of South Sulawesi Province, using resistance method, Wenner- Schlumberger configuration with 4 survey tracks and 10 metre /electrode. The resistivity survey result is 2D longitudinal section and 3D model block providing information about iron ore spread, where the largest spread is in the west area of the research territory with direction to the northeast - southwest. Resistivity data from 2D resistivity longitudinal section is achieved from measurement of track 1 to track 4 on the field which is iron ore be in resistivity $p<40$ $\mathrm{Ohm}$, andesit rock corrosion zone with $40 \mathrm{Ohm}<$ resistivity $\mathrm{p}<250 \mathrm{Ohm}$ and basalt rock zone with resistivity level $\mathrm{p}>250 \mathrm{Ohm}$.
\end{abstract}

Keywords: Iron Ore, Geoelectrical, resistivity, Wenner-Schlumberger

\section{Pendahuluan}

Besi termasuk unsur yang melimpah di permukaan bumi bahkan sampai ke inti bumi dan berbagai benda langit yang jatuh ke bumi. Sebagai logam yang paling murah dan penggunaannya sangat luas, besi menjadi logam terbesar yang diproduksi di dunia. Seiring dengan perkembangan teknologi saat ini, kebutuhan sumber daya mineral khususnya besi terus meningkat, sehingga 
penambangan bijih besi yang merupakan mineral utama untuk kebutuhan industri terus meningkat. Endapan bijih besi yang terdapat di bumi dapat terbentuk secara primer maupun sekunder. Pembentukan bijih besi primer dapat terjadi oleh proses magmatik, metasomatik kontak, dan hidrotermal. Sedangkan endapan bijih sekunder terbentuk oleh proses sedimenter, residual, dan oksidasi. Besi pada umumnya berbentuk oksida besi seperti hematite $\left(\mathrm{Fe}_{2} \mathrm{O}_{3}\right)$, magnetit $\left(\mathrm{Fe}_{3} \mathrm{O}_{4}\right)$ dan jenis batuan besi lainnya (Jensen dan Batemen, 1981).

Penelitian bijih besi dengan menggunakan geolistrik resistivitas pernah dilakukan oleh Sumartono, dkk (2013) di daerah Bukit Munung Kecamatan Sungai Betung dengan menggunakan konvigurasi Wenner menemukan bahwa berdasarkan nilai resistivitasnya, diduga merupakan mineralisasi bijih besi brown iron oxide, hematit ( $\mathrm{Fe} 2 \mathrm{O} 3)$ dan magnetit (Fe3O4). Kosidahrta, dkk (2016) di di Kabupaten Tanah Laut dengan menggunakan konfigurasi Schlumberger menemukan bahwa pada kedalaman $\pm(11-33)$ meter dengan nilai hambatan jenis berkisar antara $(2,37-5,6) \Omega m$ yang diduga adalah bijih besi Hematite (Fe2O3) dan hasil uji XRF menunjukan kandungan bijih besi (Fe) dengan nilai rata-rata sebesar $97,876 \%$, yang diperkirakan adalah Hematite. Prawira (2014) tentang "Aplikasi Metode Geolistrik Konfigurasi Wenner-Schlumberger dalam Menganalisis Jalur Vein Kromit Di Bawah Permukaan Bumi" bahwa nilai resistivitas batuan dasar (peridotite) yang didapatkan dari survei geolistrik dapat mengidentifikasikan penyebaran vein kromit di bawah permukaan.

Pada penelitian ini, identifikasi sebaran bijih besi dengan menggunakan metode geolistrik resistivitas konfigurasi WennerSchlumberger menggunakan 4 lintasan survei dengan spasi 10 meter/elektroda. Hasil survei resistivitas diolah menggunakan software Res2dinv untuk mendapatkan penampang 2-D sementara untuk mendapatkan block model resistivitas pseudo-3D data diolah menggunakan software Encom PA, yang memberikan informasi tentang sebaran bijih besi di Kabupaten Luwu Kecamatan Walanreng. Konfigurasi WennerSchlumberger sensitif terhadap adanya ketidakhomogenan lokal dan cocok untuk memetakan batuan bawah permukaan dengan cakupan yang dalam.

\section{Kondisi Geologi Daerah Penelitian}

Secara geografis, Kabupaten Luwu terletak di bagian utara Provinsi Sulawesi Selatan, dimana posisi Kabupaten Luwu terletak $2^{\circ} .34^{\prime} .45^{\prime \prime} \quad-\quad 3^{\circ} .30^{\prime} .30^{\prime \prime} \quad$ LS dan $120^{\circ} .21^{\prime} .15^{\prime \prime}$ - $121^{\circ} .43^{\prime} .11^{\prime \prime}$ BT dengan luas wilayah $3.000,25 \mathrm{~km}^{2}$. Salah satu Kecamatan yang ada di Kabupaten Luwu adalah Kecamatan Walenrang dengan luas wilayah $94,6 \mathrm{~km}^{2}$ atau hanya $3,15 \%$ dari seluruh luas wilayah Kabupaten Luwu Sulawesi Barat.

Stratigrafi daerah penelitian termasuk dalam peta geologi lembar Malili 12-21, 2013 (Djuri,dkk.1998), seperti pada Gambar 1. Urutan stragtigrafi batuan dari muda sampai tertua yang dijumpai adalah Formasi Latimojong atau Kapur Latimojong $(\mathrm{Kl})$ yang berumur Kapur dengan ketebalan \pm 1000 m. Secara umum formasi ini mengalami pemalihan lemah hingga sedang dan terdiri dari ; serpih, filitik, rijang, marmer, kuarsit dan breksi terkersikkan. Batuan ini diterobos oleh batuan beku intermediet sampai basa, di atas Formasi Latimojong diendapkan secara tidak selaras Formasi Toraja yang terdiri dari Tersier Eosen Toraja Shale (Tets) dan Tersier Eosen Toraja Limestone (Tetl) yang berumur Eosen, yang terdiri dari serpih coklat kemerahan, serpih napalan kelabu, batugamping, batupasir kuarsa, konglomerat, batugamping, dan setempat batubara. Ketebalan Formasi ini $\pm 1000 \mathrm{~m}$. Fosil Foraminifera besar pada batugamping menunjukan umur EosenMiosen sedangkan lingkungan 
pengendapannya adalah laut dangkal. Formasi ini menindih tidak selaras Formasi Latimojong dan ditindih tidak selaras oleh batuan Gunungapi Lamasi.

Secara regional Kabupaten Walanreng termasuk dalam Batuan Gunungapi Lamasi (Tplv) berupa perselingan lava, breksi dan tufa, dengan lava dan breksi merupakan batuan penyusun utamanya.
Batuan vulkanik yang terbentuk di atas formasi toraja merupakan Tersier Oligosen Lava Vulkanik (Tolv) yang berumur Oligosen karena menindih Formasi Toraja yang berumur Eosen. Batuan vulkanik ini terdiri dari aliran lava bersusunan basaltik hingga andesitik, basalt, tuff, breksi vulkanik, batupasir dan batulanau. Ketebalan satuan ini mencapai $\pm 500 \mathrm{~m}$.

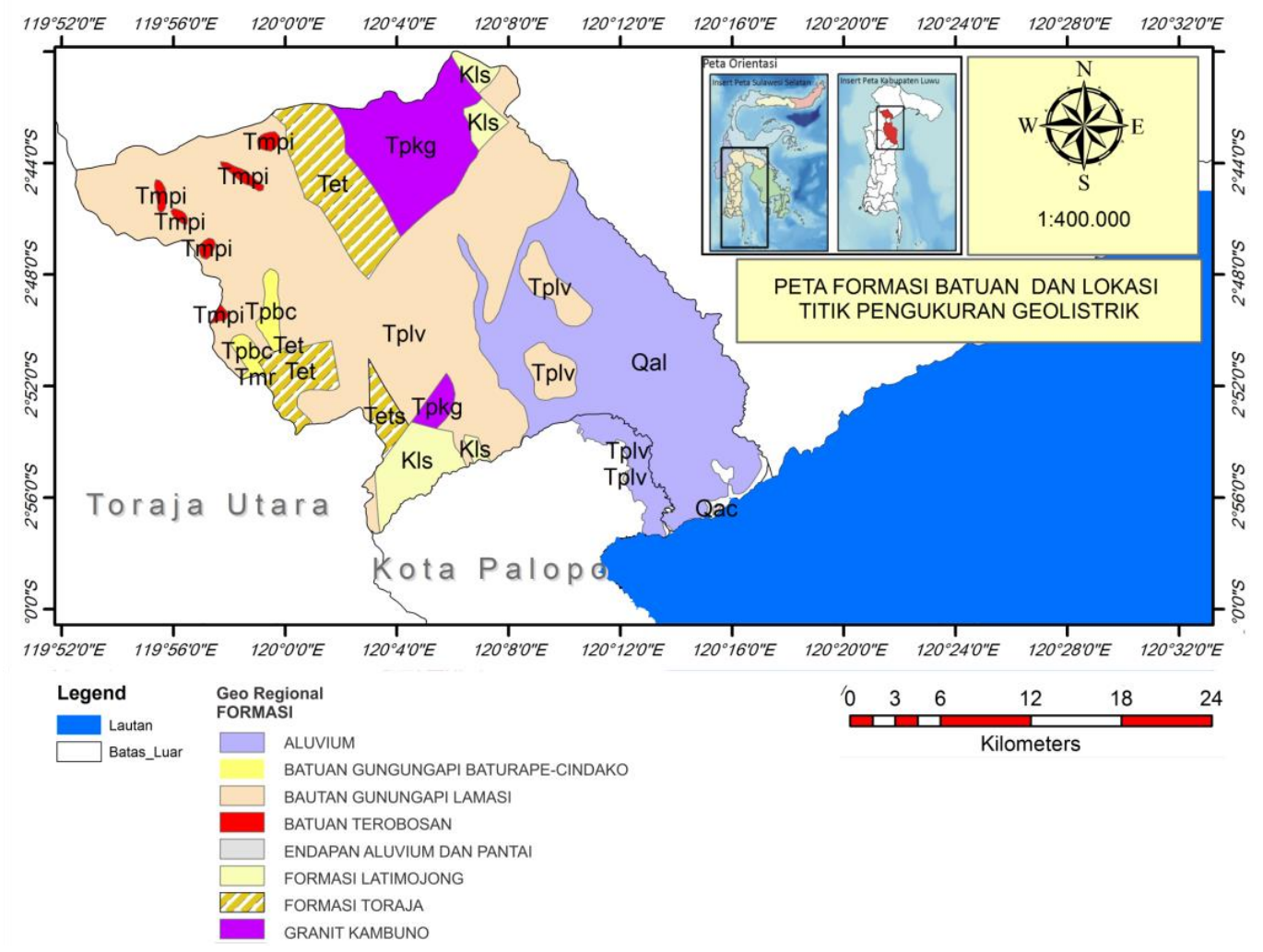

Gambar 1. Peta lokasi penelitian. (Digitasi dari peta administrasi Kabupaten Luwu, 2010)

\section{Metode Resistivitas}

Metoda resistivitas adalah salah satu metoda geofisika yang digunakan untuk menyelidiki kondisi bawah permukaan, yaitu dengan mempelajari sifat resistivitas dari lapisan batuan di dalam bumi. Prinsip kerja metode resistivitas adalah dengan mengalirkan arus listrik ke dalam bumi melalui dua buah elektroda arus, lalu mengukur distribusi potensial yang terbentuk melalui dua buah elektroda potensial (Hendrajaya,1990). Hal ini dapat dilakukan dengan menggunakan keempat elektroda yang disusun sebaris, salah satu dari dua buah elektroda yang berbeda muatan digunakan untuk mengalirkan arus listrik dan dua elektroda lainnya digunakan untuk mengukur potensial yang ditimbulkan oleh aliran arus listrik tersebut, seperti ditunjukkan pada

Gambar 2.

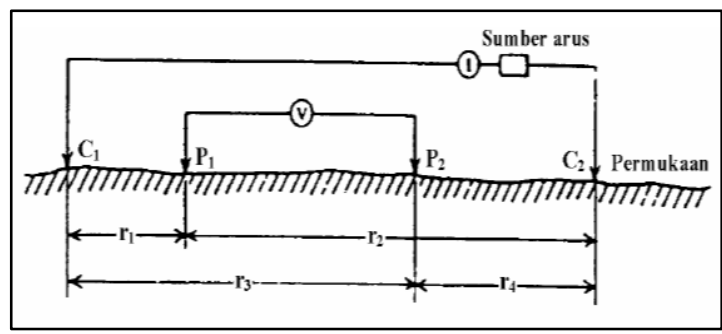

Gambar 2. Dua elektroda arus dan dua elektroda potensial di permukaan bumi yang homogen (Telford dkk,1990). 
Beda potensial antara titik $\mathrm{P}_{1}$ dan $\mathrm{P}_{2}$ adalah:

$$
\Delta V=\frac{I \rho}{2 \pi}\left\{\left(\frac{1}{r_{1}}-\frac{1}{r_{2}}\right)-\left(\frac{1}{r_{3}}-\frac{1}{r_{4}}\right)\right\}
$$

Besaran $r_{1}, r_{2}, r_{3}$, dan $r_{4}$ adalah besaran jarak, seperti diperlihatkan pada Gambar 2, jika $K=\frac{2 \pi}{\left(\frac{1}{r_{1}}-\frac{1}{r_{2}}\right)-\left(\frac{1}{r_{3}}-\frac{1}{r_{4}}\right)}$, maka persamaan (1) dapat ditulis sebagai :

$$
\rho=K \frac{\Delta V}{I}
$$

Resistivitas medium pada persamaan (2) merupakan resistivitas semu (apparent resistivity) yang diperoleh dari hasil pengukuran di lapangan. Resistivitas semu medium $\left(\rho_{a}\right)$, yang terukur dihitung berdasarkan persamaan:

$$
\rho_{a}=K \frac{\Delta V}{I}
$$

dimana:

$\rho_{a}:$ resistivitas semu $(\Omega \mathrm{m})$

$\Delta \mathrm{V}$ : potensial yang terukur $(\mathrm{mV})$

$\mathrm{I}$ : arus listrik yang mengalir ke tanah $(\mathrm{mA})$

$\mathrm{K}$ : faktor geometri konfigurasi elektroda.

Ada beberapa konfigurasi untuk tahanan jenis dalam melakukan akuisisi data. Salah satunya adalah dengan menggunakan konfigurasi Wenner-Sclumberger.

Konfigurasi ini merupakan gabungan antara konfigurasi Wenner dan konfigurasi Schlumberger yang pengaturan elektrodanya seperti pada Gambar 3. Konfigurasi Wenner-Sclumberger mempuyai penetrasi maksimum kedalaman $15 \%$ lebih baik dari konfigurasi Wenner. Faktor geometri dari konfigurasi elektroda Wenner-Schlumberger adalah :

$\mathrm{K}=\pi \mathrm{n}(\mathrm{n}+1) \mathrm{a}$

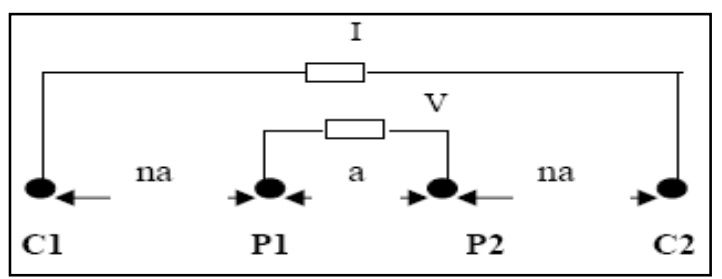

Gambar 3. Pengaturan elektroda konfigurasi Wenner-Schlumberger (Loke, 2004)

Keunggulan dari konfigurasi Wenner Schlumberger dibanding dengan konfigurasi lainnya karena elektroda arus dan elektroda potensial selalu berubahrubah, maka konfigurasi ini sensitif terhadap adanya ketidakhomogenan lokal, seperti lensa-lensa dan gawir-gawir. Jarak elektoda potensial cukup besar, maka beda potensial yang terukur di antaranya juga cukup besar sehingga pengukuran yang dilakukan cukup sensitif. Cocok untuk memetakan batuan bawah permukaan dengan cakupan yang dalam.

Nilai resistivitas batuan secara umum telah diperoleh melalui berbagai pengukuran dan dapat dijadikan sebagai acuan dalam interpretasi, karena resistivitas tertentu akan berasosiasi dengan kondisi geologi tertentu. Tabel 1, menyajikan harga resistivitas dari beberapa jenis batuan.

Tabel 2.1 Nilai Resistivitas Batuan (Telford dkk, 1990).

\begin{tabular}{lll}
\hline \multirow{2}{*}{$\begin{array}{l}\text { Jenis } \\
\text { Batuan }\end{array}$} & \multicolumn{2}{l}{ Resistivity Range $(\Omega m)$} \\
\cline { 2 - 3 } $\begin{array}{l}\text { Granite } \\
\text { porphyry }\end{array}$ & $4.5 \times 10^{3}$ & $1.3 \times 10^{6}$ \\
\hline $\begin{array}{l}\text { Diorite } \\
\text { porphyry }\end{array}$ & $1.9 \times 10^{3}$ & $2.8 \times 10^{4}$ \\
\hline Porphyrite & $10-5 \times 10^{4}$ & $3.3 \times 10^{3}$ \\
\hline $\begin{array}{l}\text { Carbonatize } \\
\text { d porphyry }\end{array}$ & $2.5 \times 10^{3}$ & $6 \times 10^{4}$ \\
\hline $\begin{array}{l}\text { Quartz } \\
\text { diorite }\end{array}$ & $2 \times 10^{4}-2 \times 1.8 \times 10^{5}$ \\
\hline Andesite & $4.5 \times 10^{4}$ & $1.7 \times 10^{2}$ \\
\hline Basalt & \multicolumn{2}{l}{$10-1.3 \times 10^{7}$} \\
\hline $\begin{array}{l}\text { Olivine } \\
\text { norite }\end{array}$ & $10^{3}-6$ & \\
\hline Peridotite & $3 \times 10^{4}$ & $6.5 \times 10^{3}$ \\
\hline Hornfels & $8 \times 10^{3}$ & $6 \times 10^{7}$ \\
\hline Schists & $20-10^{4}$ & \\
\hline Tuffs & $2 \times 10^{3}$ & $10^{5}$ \\
\hline $\begin{array}{l}\text { Slates } \\
\text { (various) }\end{array}$ & $6 \times 10^{2}$ & $4 \times 10^{7}$ \\
\hline $\begin{array}{l}\text { Gneiss } \\
\text { (various) }\end{array}$ & $6.8 \times 10^{4}$ & $3 \times 10^{6}$ \\
\hline $\begin{array}{l}\text { Skarn } \\
\text { Limestones }\end{array}$ & $2.5 \times 10^{2}$ & $2.5 \times 10^{8}$ \\
\hline Dolomite & $3.5 \times 10^{2}$ & $5 \times 10^{3}$ \\
\hline
\end{tabular}


Karakter endapan besi ini berupa endapan yang berdiri sendiri namun seringkali ditemukan berasiosiasi dengan mineral logam. Tabel 2, menyajikan nilai resistivitas beberapa jenis mineral. Dari mineral-mineral bijih besi, magnetik adalah mineral dengan kandungan $\mathrm{Fe}$ paling tinggi, tetapi terdapat dalam jumlah yang kecil sementara hematite merupakan mineral bijih utama yang dibutuhkan dalam industri besi, Telford dkk,1990.

Tabel 2. Nilai Resistivitas Beberapa Mineral (Telford dkk,1990)

\begin{tabular}{lll}
\hline Mineral & $\begin{array}{l}\text { Range } \\
(\Omega \mathrm{m})\end{array}$ & Average \\
\hline Galena & $\begin{array}{l}3 \times 10^{-5}-3 \\
\mathrm{x} 10^{2}\end{array}$ \\
\hline Chromite & $1-10^{6}$ & \\
\hline Hematite & $3.5 \times 10^{-3}$ \\
& $10^{7}$ & \\
\hline Limonite & $10^{3}-10^{7}$ \\
\hline Magnetite & $5 \times 10^{-5}-5$ \\
& $\times 10^{3}$ \\
\hline Quartz & $4 \times 10^{10}-2$ \\
& $\times 10^{14}$ \\
\hline Bismuthinite & $18-570$ & 220 \\
\hline Pyrite & $2.9 \times 10^{-5}-3 \times 10^{-1}$ \\
& 1.5 & \\
\hline Cuprite & $10^{-3}-300$ & 30 \\
\hline
\end{tabular}

\section{Metode Penelitian}

Pada kegiatan ini dilakukan pengambilan data secara langsung menggunakan konfigurasi Wenner-Sclhumberger dengan 2 lintasan dibuat sejajar kemudian 2 lintasan memotong lintasan lainnya. Panjang lintasan $280 \mathrm{~m}$ untuk lintasan 1 dan 2 sedangkan panjang lintasan 3 dan 4 adalah $150 \mathrm{~m}$ dengan jarak spasi elektroda $10 \mathrm{~m}$ semua lintasan. Data yang diperoleh dari lapangan berupa data nilai arus (I) dan nilai beda potensial (V). Faktor geometri (K) dihitung dengan menggunakan persamaan 4 dan nilai resistivitas semu $\left(\boldsymbol{\rho}_{\text {semu }}\right)$ menggunakan persamaan 3, kemudian diolah dengan menggunakan Software Res2Dinv diperoleh penampang 2-D. Dengan menggabungkan semua penampang 2-D menjadi model pseudo 3D, sehingga penyebaran bijih besi secara lateral dapat dipetakan. Bagan air penelitian seperti disajikan pada Gambar 4.

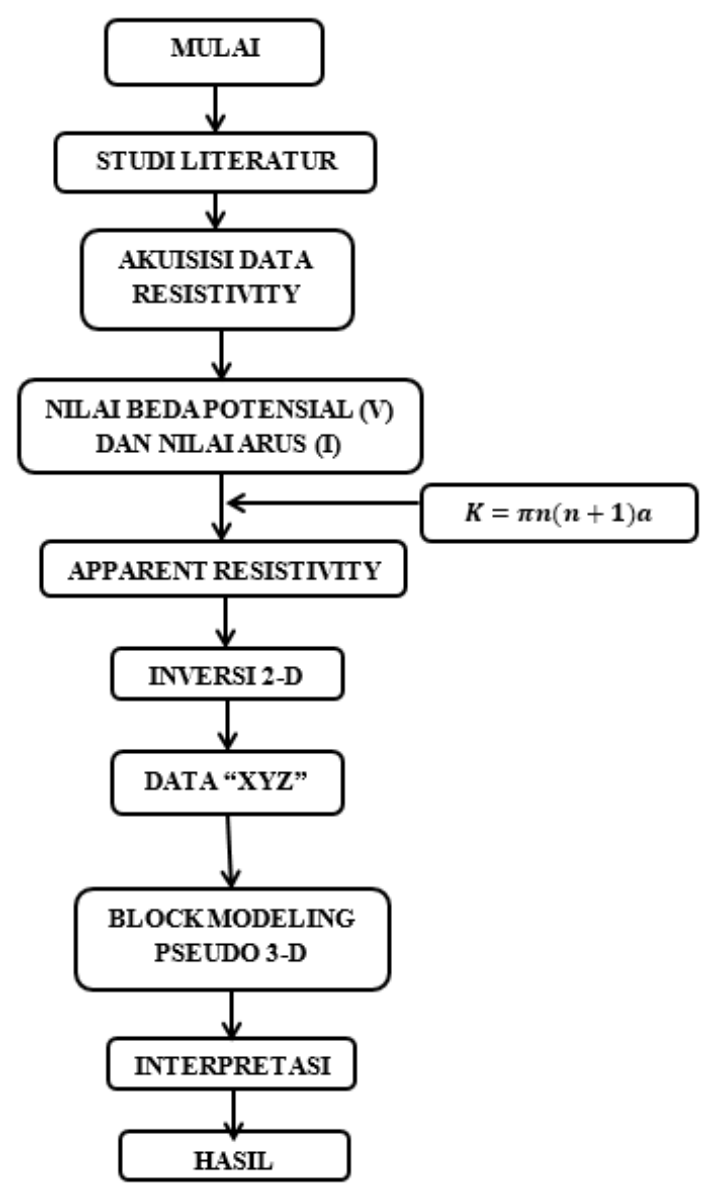

Gambar 4. Bagan Alir Penelitian

\section{Hasil dan Pembahasan}

Data yang diperoleh dari hasil pengukuran di lapangan berupa titik datum, spasi, jumlah lapisan, dan nilai resistivitas, kemudian data tersebut diolah menggunakan perangkat RES2DINV terhadap keempat lintasan pengukuran. Hasil inversi dari software ini berupa profil penampang 2-D, selain itu hasil inversi (.inv) dapat disimpan dalam bentuk koordinat (.xyz). Data (.xyz) terdiri dari akumulasi jarak elektroda dari elektroda pertama, kedalaman penetrasi, nilai resistivitas sebenarnya (true resistivity) dan konduktivitas bawah permukaan. Berdasarkan hasil pengolahan data yang 
diperoleh dari masing-masing lintasan diperoleh untuk :

Lintasan 1 : Hasil inversi berupa profil penampang 2-D disajikan pada Gambar 5, pada skala warna nila resistivitas terlihat bahwa warna biru memiliki reistivitas rendah yaitu resistivitas $\rho<40 \Omega$ m yang ditafsirkan sebagai lapisan endapan bijih besi magnetit (Telford dkk, 1990). Hal ini sesuai dengan yang ditemukan di lembah buntu Mario dan buntu Sikuku, bagian barat daerah penelitian hingga ke buntu Andulan bagian utara. Sebagai mineral petunjuk dalam zona ini adalah mineral ortoklas - biotit atau ortoklas - biotit klorit terbentuk karena adanya penambahan unsur Fe dan $\mathrm{Mg}$ yang diikuti mineral sulfida dengan kadar rendah. Boulder magnetis yang tersebar di aliran sungai lamasi diperkirakan berasal dari zona potasik. Variasi warna jingga sampai ungu tua dengan $\rho>250 \Omega \mathrm{m}$ diperkirakan merupakan batuan basal berdasarkan tabel resistivitas (Telford dkk, 1990), hal tersebut bisa diartikan sebagai batuan dasar di posisi elektroda 60 dengan kedalaman 10 - $20 \mathrm{~m}$, posisi elektroda 160 dengan kedalaman 5 - $10 \mathrm{~m}$, dan posisi elektroda 200 dengan kedalaman 5 - 15 m merupakan boulder - boulder batuan basal yang belum mengalami pemampatan dan sedimentasi. Zona pelapukan $(40 \Omega \mathrm{m}<\rho$ $<250 \Omega \mathrm{m})$ memiliki fragmen-fragmen magnetit berukuran kerikil dibandingkan dengan zona batuan basal berasal dari batuan andesit yang mengalami pelapukan.

Lintasan 2 : Profil penampang 2-D disajikan pada Gambar 6, yang memperlihatkan bahwa zona lapisan endapan bijih besi magnetit dengan resistivitas yang rendah yaitu $\rho<40 \Omega$ m terdapat di sepanjang lintasan 2 pada kedalaman $10 \mathrm{~m}-40 \mathrm{~m}$. Pada posisi elektroda 40 dengan kedalaman $5 \mathrm{~m}$, pada posisi elektroda 80 dengan kedalaman 10 $\mathrm{m}$, posisi elektroda 250 kedalaman $5 \mathrm{~m}$ menunjukkan indikasi adanya boulderboulder basal. Zona pelapukan $(40 \Omega \mathrm{m}<\rho$
$<250 \Omega \mathrm{m})$ memiliki fragmen-fragmen magnetit berukuran kerikil dibandingkan dengan zona batuan basalt berasal dari batuan andesit yang mengalami pelapukan. Zona batuan basal dengan $(\rho>250 \Omega \mathrm{m})$ berada pada posisi elektroda 40 dengan kedalaman $35 \mathrm{~m}$, dan elektroda 160 dengan luasan cukup besar, memanjang sekitar $\pm 40 \mathrm{~m}$ dengan kedalaman $45 \mathrm{~m}$.

Lintasan 3 : Profil penampang 2-D hasil inversi disajikan pada Gambar 7, diperoleh lapisan endapan bijih besi magnetit dengan $\rho<40 \Omega$ di perkirakan terdapat pada posisi elektroda 50 dengan kedalaman $15-40 \mathrm{~m}$, posisi elektroda 80 dengan kedalaman $5-15 \mathrm{~m}$, dan posisi elektroda 90 memanjang sekitar $\pm 45 \mathrm{~m}$ dengan kedalaman 5-45 m lapisan bijih besi pada lintasan 3 tidak sebanyak yang terdapat pada lintasan 1 dan lintasan 2 . Zona pelapukan dengan $40 \Omega \mathrm{m}<\rho<250$ $\Omega \mathrm{m}$ lapisan zona pelapukan (weathering zone) ini memiliki fragmen-fragmen magnetit berukuran kerikil dibandingkan dengan zona batuan basal yang diperkirakan berasal dari batuan andesit yang mengalami pelapukan dengan variasi warna biru muda sampai warna coklat. Zona batuan basal $(\rho>250 \Omega \mathrm{m}$ ) yang berada pada posisi elektroda 20 dengan kedalaman $5-15 \mathrm{~m}$, posisi elektroda 100 dengan kedalaman $5 \mathrm{~m}$. Kemungkinan lain pada daerah ini adalah kondisi tanah lahan yang bersifat sangat padat/keras. Kondisi tersebut mengindikasikan tanah pada lahan ini memiliki sifat porositas yang kecil.

Lintasan 4: Berdasarkan profil penampang 2-D pada Gambar 8, memperlihatkan bahwa $\rho<40 \Omega \mathrm{m}$ ditafsirkan sebagai lapisan endapan bijih besi magnetit (Telford dkk, 1990) sebagaimana yang diketahui mineral-mineral bijih besi merupakan pengantar listrik yang baik (bersifat konduktif) atau nilai tahan jenisnya sangat rendah, terdapat pada posisi elektroda 20 dengan kedalaman 2 $5 \mathrm{~m}$, posisi elektroda 40 memanjang \pm 70 m dengan kedalaman $5-20 \mathrm{~m}$, dan pada 
posisi elektroda 80 dengan kedalaman 30 m. Zona pelapukan dimana $40 \Omega \mathrm{m}<\rho<$ $250 \Omega \mathrm{m}$ lapisan zona pelapukan (weathering zone) ini memiliki fragmenfragmen magnetit berukuran kerikil sehingga lapisan ini memiliki tahanan jenis lebih kecil dibandingan dengan zona batuan basal yang diperkirakan berasal dari batuan andesit yang mengalami pelapukan. Zona batuan basal $(\rho>250$ $\Omega \mathrm{m})$ diperkirakan berada pada elektroda 60 dengan kedalaman $5-10 \mathrm{~m}$.

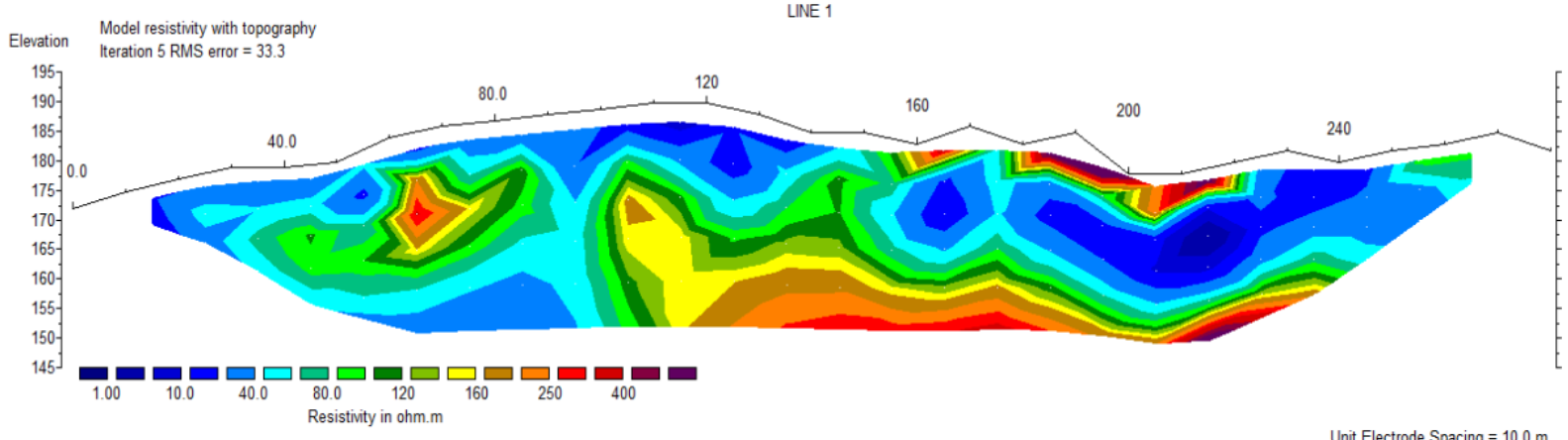

Horizontal scale is 45.89 pixels per unit spacing

Vertical exaggeration in model section display $=1.00$

First electrode is located at $0.0 \mathrm{~m}$.

Gambar 5. Penampang 2-D lintasan 1

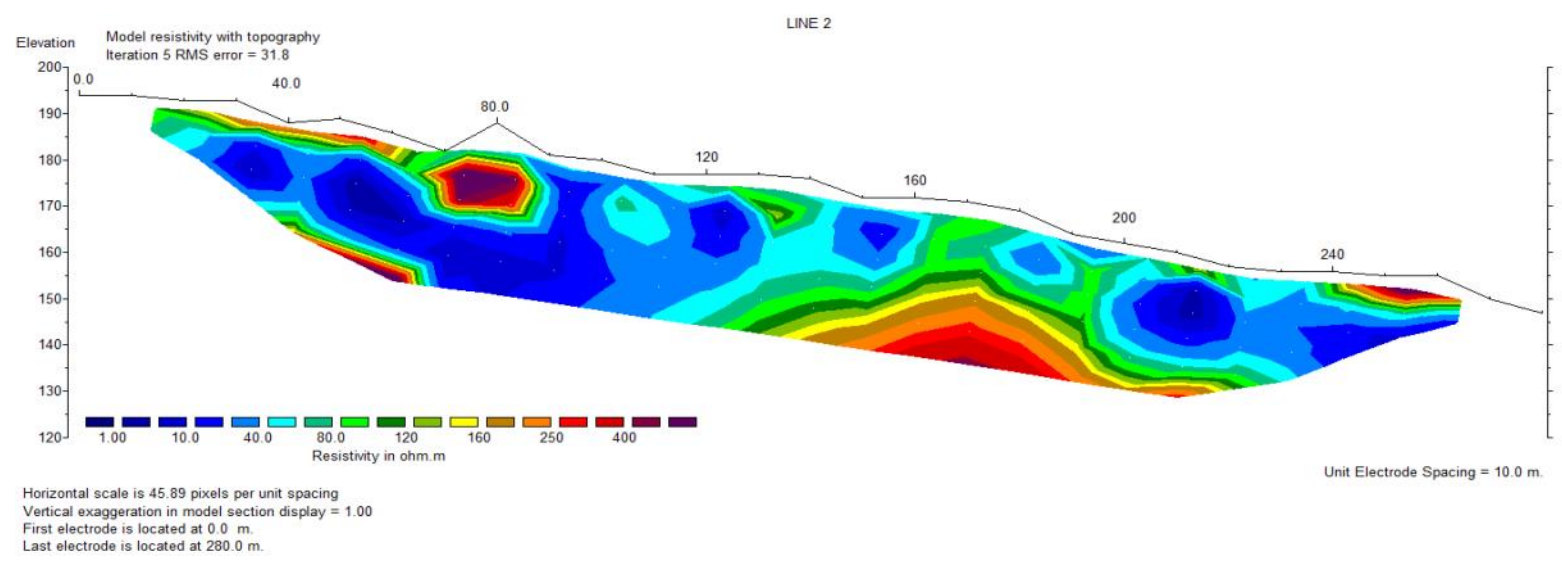

Gambar 6. Penampang 2-D Lintasan 2

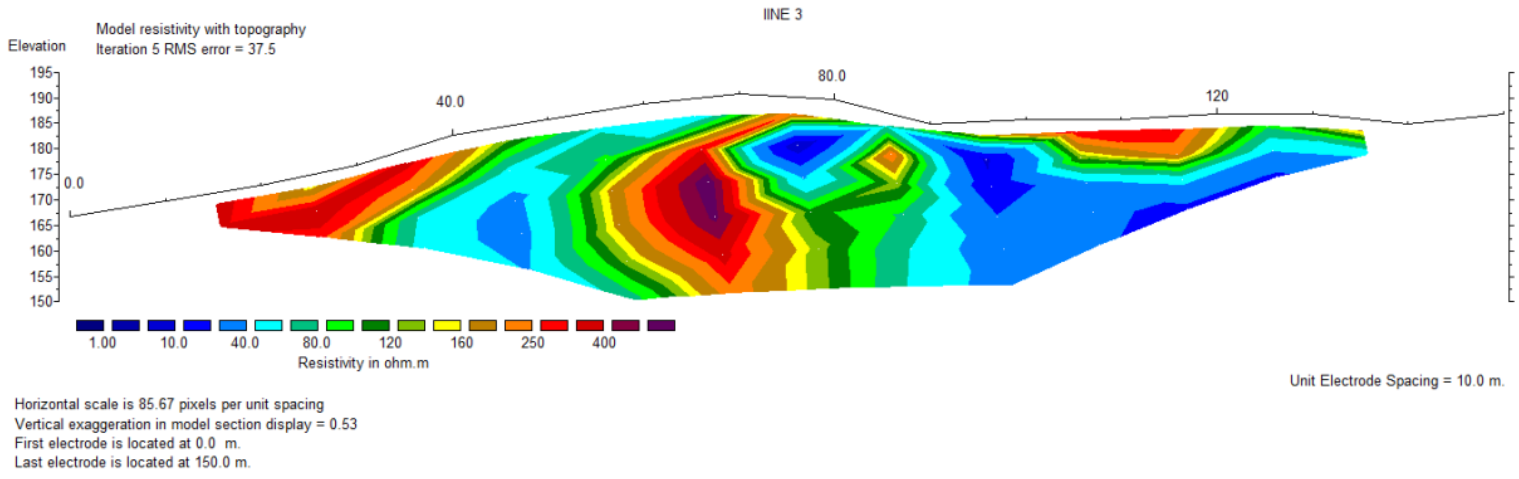

Gambar 7. Penampang 2-D Lintasan 3 


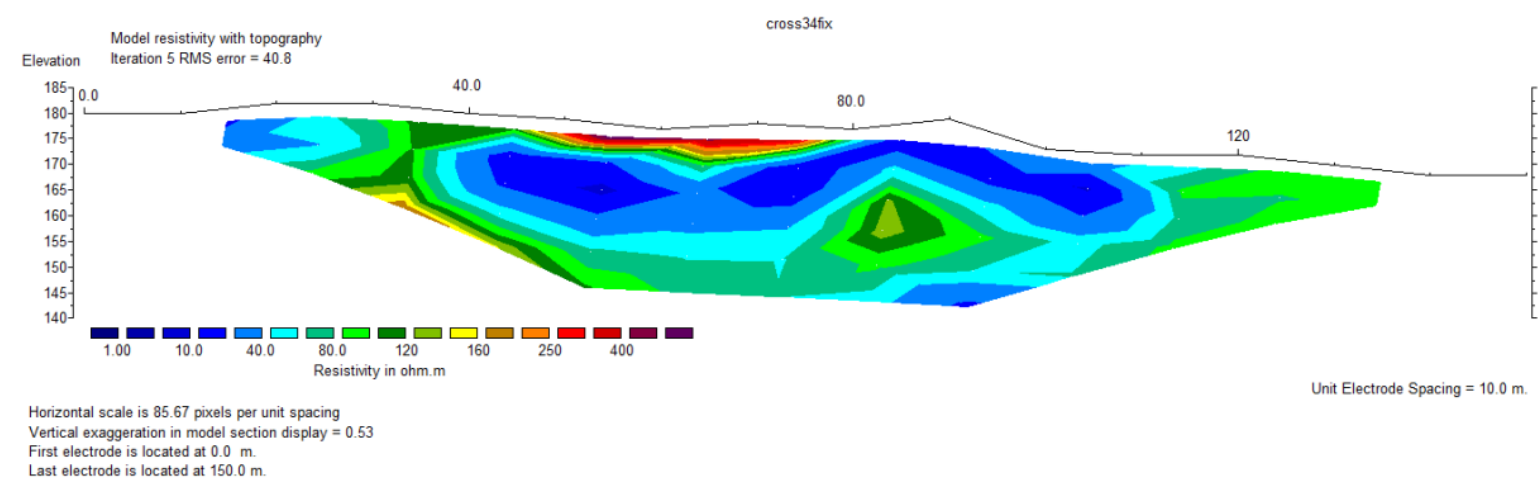

Gambar 8. Penampang 2-D Lintasan 4

Data dari penampang 2-D lintasan 1 sampai lintasan 4 dilakukan penggabungan dari pengabungan data tersebut kemudian diolah pada software Encom PA. Hasil Penggabungan dari ke empat lintasan ini dimaksudkan untuk memperoleh model pseudo 3-D dengan prinsip ektrapolasi, dengan membuat pseudo 3-D dapat memberikan gambaran yang jelas mengenai sebaran bijih besi magnetit dan batas antara jenis tanah atau batuan mana yang memiliki resistivitas rendah dan jenis tanah atau batuan yang memiliki nilai resistivitas tinggi. Hasil 3-D dibuat penyesuaian terhadap elevasi tertinggi titik data setiap lintasan seperti pada Gambar 9.

Seperti halnya pada penampang 2-D untuk model pseudo 3-D dalam menentukan zona resistivitas rendah $(\rho<40 \Omega \mathrm{m})$, ditandai dengan warna biru sampai biru pekat yang menandakan bahwa zona tersebut merupakan lapisan terdapatnya endapan bijih besi magnetit dan zona resistivitas dengan nilai $40 \Omega \mathrm{m}<\rho<250$ $\Omega m$ yang ditandai dengan warna hijau muda sampai warna jingga yang menandakan bahwa zona tersebut merupakan zona pelapukan batuan andesit sedangkan zona batuan basal ditandai dengan warna merah.

Gambar 10. Merupakan profil 3-D yang diidentifikasikan sebagai zona sebaran bijih besi, dimana nilai resistivitasnya rendah yaitu $\rho<40 \Omega$ m dengan variasi warna biru muda hingga biru tua yang menyatakan zona tersebut diduga merupakan zona lapisan endapan bijih besi magnetit, sesuai dengan yang ditemukan bagian barat daerah penelitian yaitu di lembah buntu Mario dan buntu Sikuku hingga ke buntu Andulan bagian utara ada boulder magnetis yang tersebar di aliran sungai lamasi diperkirakan berasal dari zona potasik. Hasil ini mirip dengan hasil yang diperoleh oleh Kosidahrta, dkk (2016), yaitu pada kedalaman $\pm(11-33)$ meter dengan nilai resistivitas rendah berkisar antara $(2,37$ - 5,6) $\Omega \mathrm{m}$ yang diduga adalah bijih besi Hematit (Fe2O3). Pada gambar diatas terlihat penyebaran bijih besi magnetit terbesar berada di sebelah barat daerah penelitian dengan arah timur laut - barat daya. Bagian barat lokasi penyelidikan khususnya pada zona sesar geser di buntu Santandung dijumpai breksi vulkanik yang dicirikan dengan penggantian mineral biotit menjadi klorit. Ciri fisik yang dijumpai di lapangan adalah perubahan warna pada batuan yang teralterasi menjadi berwarna hijau hingga kehitaman yang mengandung nilai kemagnetan sedang - tinggi, sifat kemagnetan pada batuan basal lebih didominasi oleh klorit hasil alterasi dari pragmen biotit pada satuan batuan breksi vulkanik dan basal . 


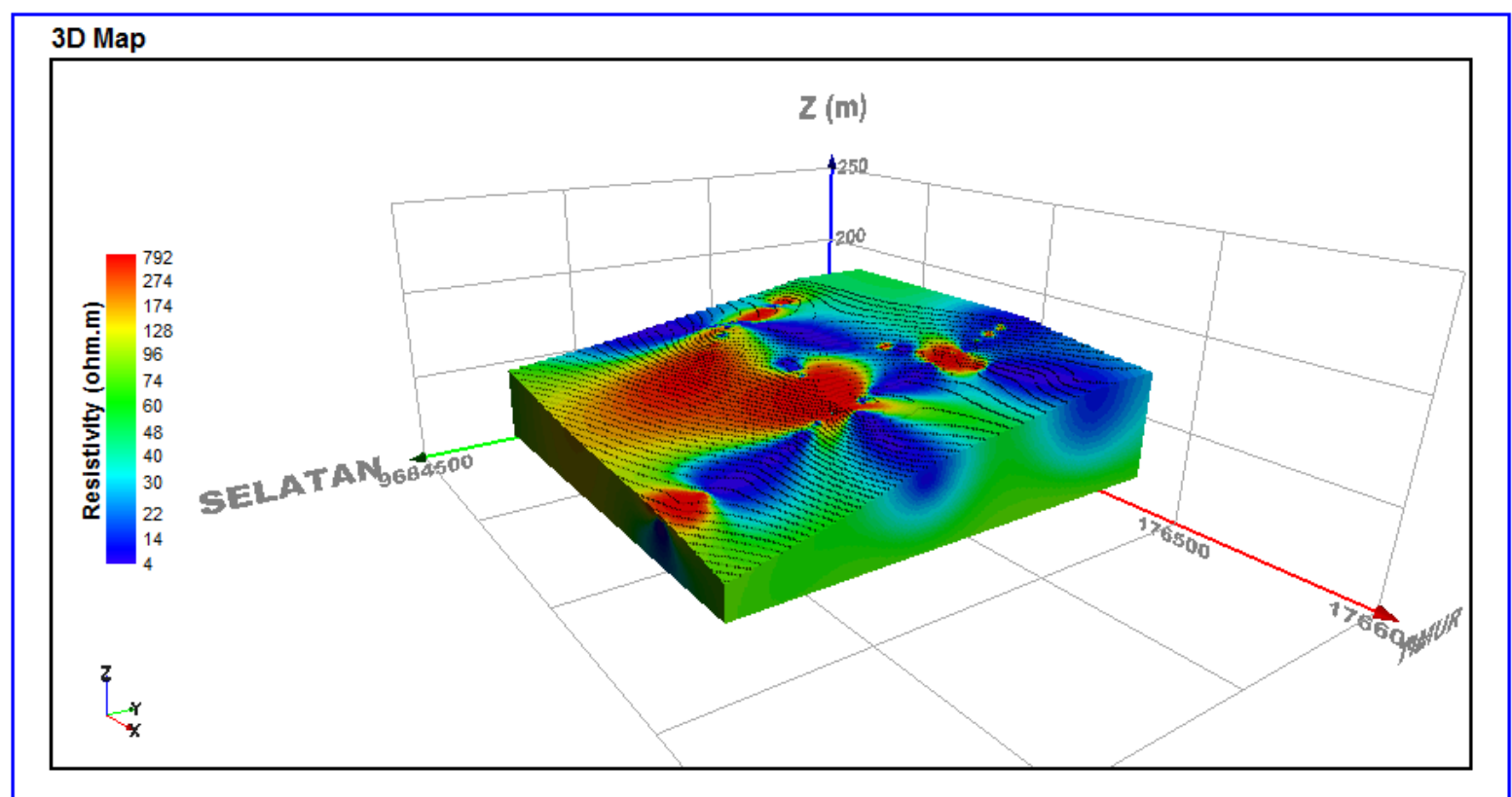

Gambar 9. Profil pseudo 3-D untuk Lintasan 1-4

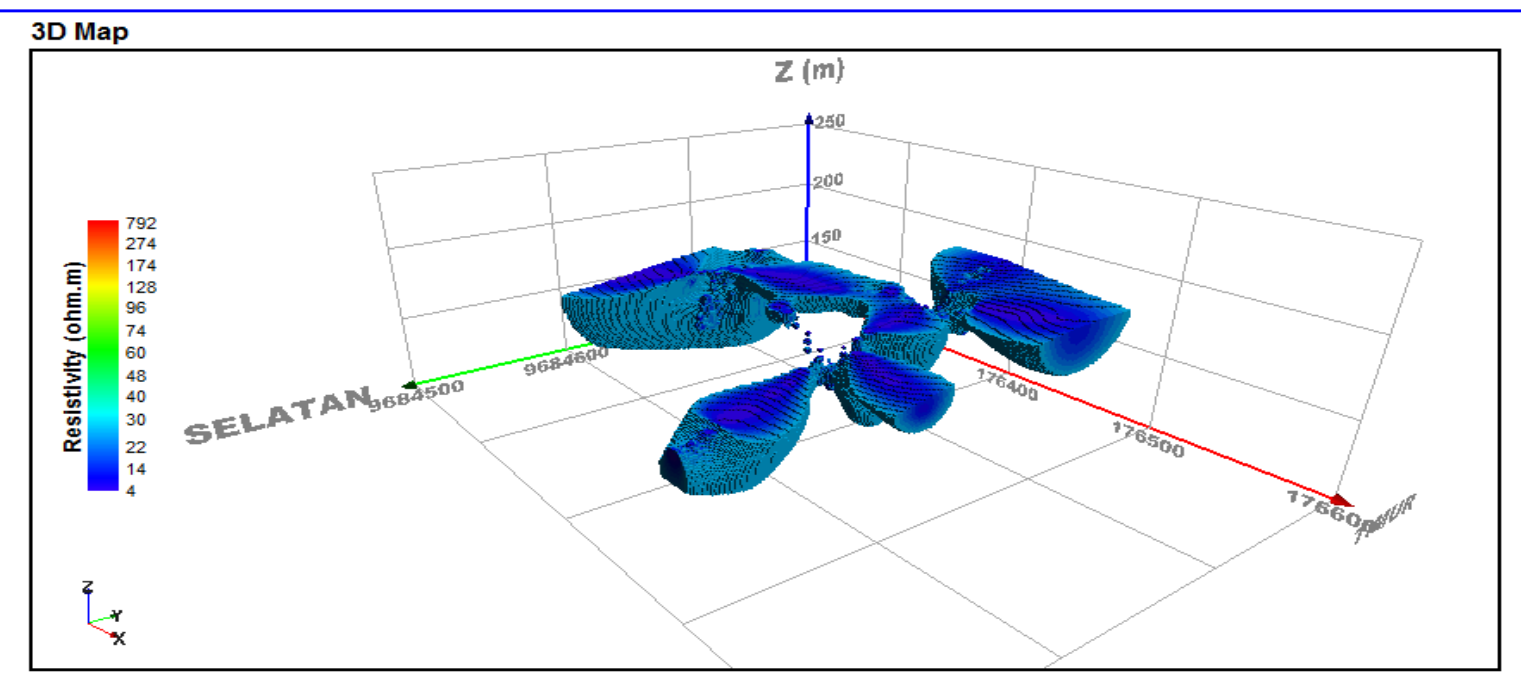

Gambar 10. Sebaran bijih besi dalam bentuk 3-D

Bagian selatan daerah penyelidikan dijumpai zona alterasi propilik, dimungkinkan terjadi oleh zona ubahan yang sangat dekat dengan daerah intrusi khususnya pada oleh sistem stocwork yang terisi oleh mineral karbonat. Pengkayaan mineral pada zona ini tidak terlalu tinggi. Pirit umum dijumpai dalam bentuk pirit halus yang tersebar pada rekahan batuan ataupun bersifat dissemineted, namun keterdapatannya dominan sebagai pengisi rekahan. Sulfida halus yang mengisi rekahan membentuk banded tipis pada zona batuan yang mengalami alterasi ini.
Pada batuan breksi vulkanik, mineralisasi umumnya dijumpai pada matriks yaitu pada rekahan yang terbentuk karena adanya kekar. Kekar tersebut terisi oleh mineral alterasi yang kadang ikut membawa mineral bijih besi seperti sulfida halus.

\section{Kesimpulan}

Berdasarkan analisis dan interpretasi data yang sudah dilakukan maka dapat diperoleh kesimpulan sebagai berikut : 
1. Block model pseudo 3-D dapat memetakan penyebaran bijih besi magnetit yang penyebaran terbesar berada di sebelah barat daerah penelitian dengan arah timur laut barat daya.

2. Data resistivitas dari penampang resistivitas 2-D yang diperoleh dari pengukuran lintasan 1 sampai dengan pengukuran lintasan 4 di lapangan yaitu zona lapisan bijih besi magnetit berada pada resistivitas $\rho<40 \Omega \mathrm{m}$, zona pelapukan batuan andesit dengan resistivitas $40 \Omega \mathrm{m}<\rho<250 \Omega \mathrm{m}$ dan zona batuan basal dengan resistivitas tinggi $\rho>250 \Omega \mathrm{m}$, sesuai dengan yang ditemukan bagian barat daerah penelitian yaitu di lembah buntu Mario dan buntu Sikuku hingga ke buntu Andulan bagian utara ada boulder magnetis yang tersebar di aliran sungai lamasi diperkirakan berasal dari zona potasik.

\section{DAFTAR PUSTAKA}

Djuri, Sudjatmiko, 1998. Peta Geologi Lembar Majene dan Bagian Barat Lembar Palopo, Sulawesi. Pusat Penelitian dan Pengembangan Geologi. Bandung.

Hendrajaya, L.dan Arif, I. 1990. Geolistrik Tahanan Jenis. Monograf metoda Eksplorasi. Laboratorium Fisika Bumi. ITB. Bandung

Jensen, M., \& Bateman, A.M., 1981. Economic Mineral Deposits. Canada : Jhon Wiley and Sons Inc.

Kosidahrta, R., Wahyono, S.C., Suarso, E., 2016 Identifikasi Bijih Besi Menggunakan Metode Geolistrik Schlumberger di Kabupaten Tanah Laut Jurnal Fisika FLUX, Volume 13, Nomor 2, Agustus 2016.

Loke, M.H. 2004. 2-D and 3-D Electrical Imaging Surveys. Tutorial. email: drmhloke@yahoo.com

Prawira, Y.2014.Aplikasi Metode Geolistrik Konfigurasi WennerSchlumberger dalam Menganalisis
Alur Vein Kromit Di Bawah Permukaan Bumi. Skripsi.

Universitas Hasanuddin. Makassar. Sumartono, W., Arman Y., Putra, Y.S. 2013. Identifikasi Sebaran Kandungan Bijih Besi di Kabupaten Bengkayang Menggunakan Metode Geolistrik Resistivitas. PRISMA FISIKA, Vol. I, No. 1, Hal. 14 - 21.

Telford, W. M., Geldart, L. P., \& Sheriff R. E. 1990. Applied Geophysics $\left(2^{\text {nd }} e d\right)$. Cambridge University Press : New York. 